\title{
Maurizio Galderisi. In Memoriam
}

\author{
Giovanni de Simone ${ }^{1}\left([) \cdot\right.$ Bruno Trimarco $^{1}$
}

Received: 8 April 2020 / Accepted: 25 April 2020 / Published online: 4 May 2020

(C) Italian Society of Hypertension 2020

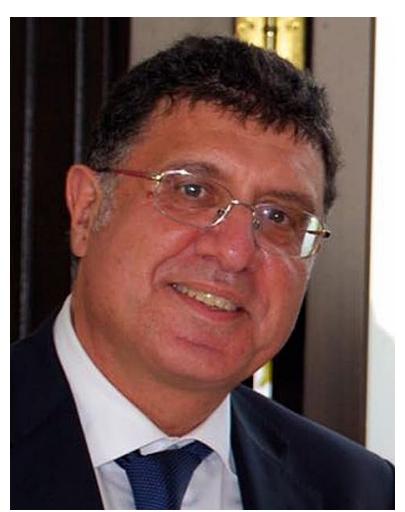

Part of us is gone, taken away by COVID-19. An immense loss for European and world cardiology. A great clinical cardiologist and a rare researcher. One of the greatest echocardiographers in the world.

Maurizio Galderisi, was 65. He was Professor of Medicine at the University of Naples Federico II in Italy. He began his career at the end of the 70's, in the group of the Cardiology Service, led by Prof. Oreste de Divitiis, in the Institute of Internal Medicine of the University of Naples Federico II directed by Prof. Mario Mancini. I (Giovanni) was his mentor, and together we developed high interest for non-invasive cardiology. Together we took the first steps with the first echocardiographs and learned to auscultate heart's sounds by making phonocardiograms.

After I (Giovanni) moved to USA in 1988, we maintained a strict contact, not easy, because email technology was just at the beginning. Right afterwards my Cornell settlement, my friend Daniel Levy moved to the Framingham Heart Study, and a great opportunity arose for Maurizio to work with him at Framingham, in a visiting researcher position.

Giovanni de Simone

simogi@unina.it

1 Hypertension Research Center, Department of Advanced Biomedical Sciences, Federico II University Hospital, via S. Pansini 5, bld 1, 80131 Naples, Italy
When he moved there, I was a little concerned about his integration in such a competitive group. It was a big underestimation of his ability to interact with peers and scientists. He lived in Boston for 1 year and, working very hard under the Daniel's guidance, he developed critical analyses on diabetic cardiomyopathy, signing the first epidemiological study on this key topic, which became one of the most quoted paper on cardiovascular complication in diabetes. He left an indelible trace in the Framingham Heart Study team and continued to cooperate with that group.

We have learned so much from each other. In recent years, it was he who mastered us with the new ultrasonic technologies of which he had become one of the greatest experts in Europe, working very hard in the laboratory as well as in our CCU. The potential of our Echocardiography Laboratory has been increased tenfold, once he took it over.

His brilliant intelligence led him to develop rapidly (already during his stay in Framingham) lines of clinical research different from those in which we have been growing. He was an independent spirit.

Over the years Maurizio's scientific growth has been amazing. He has been a pioneer in many new ultrasonic techniques, including strain imaging and the now widespread handheld ultrasound (POCUS), another topic in which his forward-looking was longer than ours (at the time of the NAUSICA study, we were a little skeptic). His reputation as a cardiologist and echocardiographer crossed the continental borders. He was called upon to co-sign many intercontinental recommendations (American and European). He became Vice-President of the European Association of Cardiovascular Imaging, the largest and most influential scientific society in the field of cardiovascular imaging, and this year he would have been running for President, a position that most probably could be easily achieved.

He has also been a pioneer in understanding the importance of systematic cardiological control in cancer patients undergoing chemotherapy, up to promoting the establishment of a Council on Cardio-oncology within the European Society of Cardiology, and a European Registry. He also led our collective effort to promote the initiation of the 
trans-departmental Program of Cardiological Surveillance of Hematologic-Oncologic Patients, as a strategic asset of our Cardiology, at the Federico II University Hospital in Naples, and was appointed as the Director of this critical program.

Alongside his scientific and clinical commitments, he loved teaching and training students, fellows and residents. He raised a group of extraordinary cardiologist-internists with great instrumental skills.

Maurizio was not only a spectacular physician and scientist. He was a splendid person of great generosity and availability to interact with peers, patients and fellows. His sense of ethics, the perception that his job was also a mission, was rare. In many occasions his bravery dealing with very difficult situations has been distinctive. He has never made any decision that was not in the pure interest of patients. The meaning of "defensive medicine" was totally unknown in his mind. Possibly his bravery meant his life.

His passing away has shocked Italy and many newspapers reported the tragic news. This loss hits the scientific community and moves immense grief in many friends.

We have lost a friend that could never be replaced.

Farewell, Mau. Sit tibi terra levis

Bruno Trimarco 